\title{
Smart textile gloves for luge athletes paddling monitoring
}

\author{
Katrina Dimitre ${ }^{1}$, Alexei Katashev ${ }^{2}$, Alexander Okss ${ }^{3}$ \\ $1,2,3$ Riga Technical University, Latvia \\ E-mails: ${ }^{1}$ katrina.dimitre@gmail.com ${ }^{2}$ katashev@latnet.lv(corresponding author), ${ }^{3}$ siaesta@gmail.com \\ (Received 1 March 2016; accepted 28 April 2016)
}

\begin{abstract}
Results of the luge athletes strongly depend on the successful start. While number of methods successfully analysed movements around start handles, still there is lack of methods to monitor paddling strokes. Present paper demonstrates smart textile gloves, designed for such a purpose. Developed gloves allow to measure timing of the arms strokes as well as easily distinguish between good stroke, when athlete's palms are in full contact with ice, and insufficient one, when fingers just slide over ice without providing good push.
\end{abstract}

Keywords: luge start, paddling, athlete performance, wearables, smart textile.

\section{Introduction}

Although the first documented sled races took place in mid-15th century, the first modern luge competitions were organised in 1883 [1]. From 1964, luge is included in the Winter Olympic Games program. Despite of long history and high technical progress in sled design, the biomechanical performance of luge athletes - "sliders" found rather limited interest of researchers. Still, it was demonstrated [2] that high starting speed is one of the key points in achieving better results in luge. Number of researchers paid their attention exactly to the analysis of luge start [3, $4,5]$.

The starting phase includes three major steps: pulling and pushing starting handles to thrust luge into the track, paddling with special spiked glow for a first 7 meters of track, changing position to the one of the best aerodynamics [6]. The majority of papers concentrated mainly on propulsion form the handles. For this, the number of techniques, such as use of tensometric handles [3], high speed cinematographic [3, 5], simulation stands [4], motion capture technique [5] were applied. Besides, the second phase of the start, i.e. paddling, was studied in a less extent. One could mention the work of Lembert et al. [7], where special conveyor belts were installed on the simulation start stage to measure the force of the arm strokes. This technique obviously is not suitable for the evaluation of the paddling strokes during training at the real luge track.

The aim of the present work is development of the sensing gloves, applicable for the recording and analysis of the paddling efforts.

\section{Methods}

Figure 1 demonstrates design of the sensing glow. Velostat ${ }^{\circledR}$ based piesoresistive sandwich type sensors (Fig. 1a) were attached to the tips of index, middle and ring fingers as well as to the fingers' base (Fig. 1b). Metallic spiked pads cover the fingertips sensors, being attached to the gloves in a manner, usual for the luge athletes. Resistivity of the sensors were measured using wireless data registration unit BioRadio ${ }^{\circledR}$ (manufacturer Great Lake Neurotechnologies, formerly Clevemed Inc). The unit was equipped with custom - made resistivity - voltage transducer.

Paddling arm strokes were recorded with the kind assistance of the Latvian luge team member Arturs Darznieks. The sportsman was instructed to perform paddling on his best, providing firm contact of the palms with ice, as well as simulate insufficient strokes, when fingers are sliding over the ice surface, and poor hands synchronization, when right and left hands contacts ice at 
slightly different instants. All tests were performed at the luge start training stage at the luge and bobsleigh track in Sigulda, Latvia.

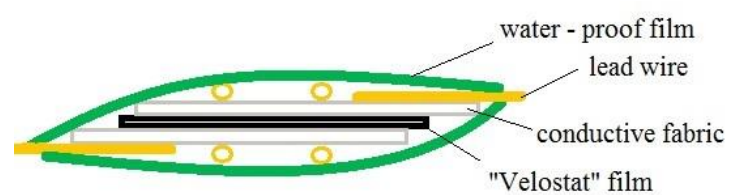

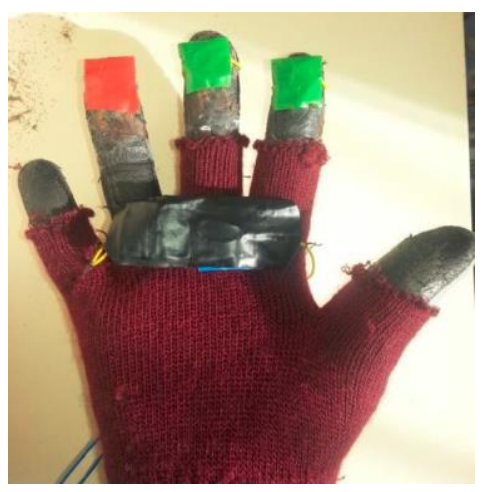

b

Fig. 1. Cross-section of the Velostat ${ }^{\circledR}$ pressure sensor (a) and design of the sensing glove (b)

\section{Results}

Figure 2 demonstrates typical recording, obtained during puddling stroke from the right hand index finger. The pattern, obtained at firm contact between ice and athlete's palm has noticeably longer duration and amplitude, comparing with "poor" stroke. The patterns, obtained from other fingers, as well as from the left hand fingers, are similar to one at the Fig. 2. Time shifts due to poor synchronization of left and right hands are easily observable, as well.

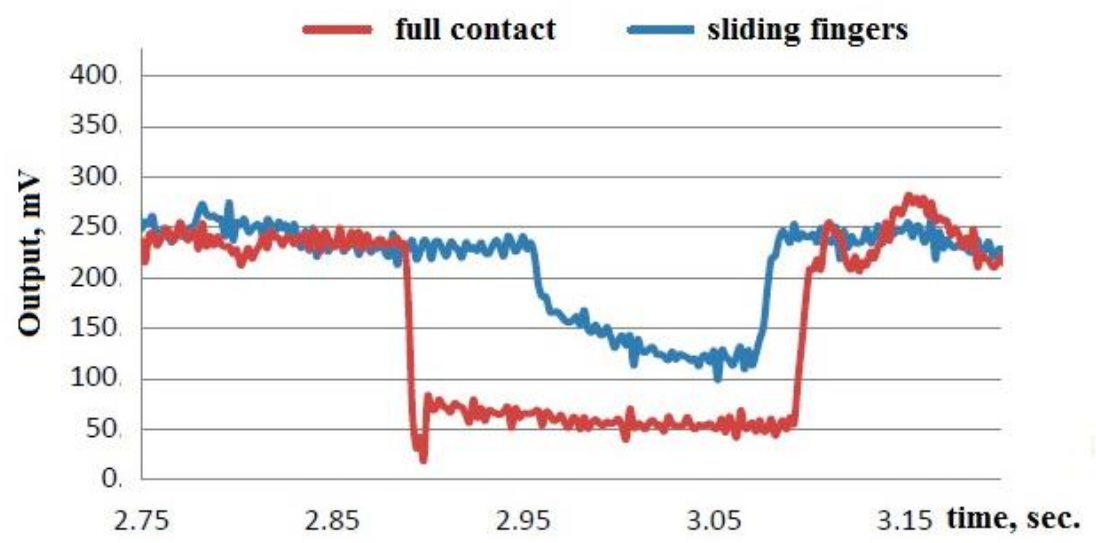

Fig. 2. Typical paddling stroke patterns for the right hand index finger

\section{Conclusions}

Developed smart textile gloves demonstrated ability to monitor luge start paddling strokes, measure time intervals between left and right arms strokes and distinguish between good stroke, when athlete's palms are in full contact with ice, and poor stroke, when fingers slides over ice.

\section{Acknowledgements}

This research was carried out in the framework of RTU project "Smart textile equipment for effective athlete training" under sponsorship of the Latvian luge federation. 


\section{References}

[1] USA Luge Association [online]. 2016. United States Olympic Committee [cited 29 February 2016]. Available from Internet: http://www.teamusa.org/usa-luge/history-and-fast-facts

[2] Bruggemann, G. P.; Morlock, M.; Zatsiorsky, V. M. 1997. Analysis of the bobsled men's luge events at the XVII Olympic Winter Games in Lillehammer, Journal of Applied Biomechanics 13(1): 98-108. http://dx.doi.org/10.1123/jab.13.1.98

[3] Young, K., et al. 1986. Biomechanical analysis of the luge start, American Society of Mechanical Engineers, Design Engineering Division 1: 81.

[4] Platzer, H.-P.; Raschner, C.; Patterson, C. 2009. Performance-determining physiological factors in the luge start, Journal of Sports Sciences 27(3): 221-226. http://dx.doi.org/10.1080/02640410802400799

[5] Fedotova, V.; Pilipivs, V. 2010. Biomechanical patterns of starting technique during training and competitive events for junior lugers, in IFMBE Proceedings of 6th World Congress of Biomechanics, August 1-6, 2010, Singapore. Berlin Heidelberg: Springer, 282-285. http://dx.doi.org/10.1007/978-3-642-14515-5_73

[6] Layton, J. 2006. How luge works [online]. HowStuffWorks [cited 7 February 2016]. Available from Internet:

http://adventure.howstuffworks.com/outdoor-activities/snow-sports/luge.htm

[7] Lembert, S.; Schachner, O.; Raschner, C. 2011. Development of a measurement and feedback training tool for the arm strokes of high-performance luge athletes, Journal of Sports Sciences, 29(15): 15931601. http://dx.doi.org/10.1080/02640414.2011.608433 